\title{
Prospective Newborn Screening for Sickle Cell Disease and Other Inherited Blood Disorders in Central Malawi
}

OPEN ACCESS

Edited by: Salvatore Panico, University of Naples Federico II, Italy

*Correspondence: Gerald Tegha getegha@gmail.com

Specialty section: This article was submitted to, a section of the journal International Journal of Public Health

Received: 14 November 2020 Accepted: 11 June 2021 Published: 29 June 2021

Citation:

Tegha G, Topazian HM, Kamthunzi P.

Howard T, Tembo Z, Mvalo T, Chome N, Kumwenda W, Mkochi T, Hernandez A, Ataga KI, Hoffman IF and Ware RE (2021) Prospective Newborn Screening for Sickle Cell Disease and Other Inherited Blood Disorders in Central Malawi. Int J Public Health 66:629338. doi: 10.3389/ijph.2021.629338

\begin{abstract}
Gerald Tegha ${ }^{1 *}$, Hillary M. Topazian ${ }^{1,2}$, Portia Kamthunzi ${ }^{1,3}$, Thad Howard ${ }^{4}$, Zondwayo Tembo ${ }^{1}$, Tisungane Mvalo ${ }^{1,5}$, Nelecy Chome ${ }^{1}$, Wiza Kumwenda ${ }^{1}$, Tawonga Mkochi ${ }^{1}$, Arielle Hernandez ${ }^{4}$, Kenneth I. Ataga ${ }^{6}$, Irving F. Hoffman ${ }^{1,3}$ and Russell E. Ware ${ }^{4,7,8}$

${ }^{1}$ University of North Carolina Project-Malawi, Lilongwe, Malawi, ${ }^{2}$ Department of Epidemiology, University of North Carolina, Chapel Hill, NC, United States, ${ }^{3}$ Institute for Global Health and Infectious Diseases, University of North Carolina, Chapel Hill, NC, United States, ${ }^{4}$ Division of Hematology, Cincinnati Children's Hospital Medical Center, Cincinnati, OH, United States, ${ }^{5}$ Department of Pediatrics, University of North Carolina, Chapel Hill, NC, United States, ${ }^{6}$ Center for Sickle Cell Disease, The University of Tennessee Health Science Center, Memphis, TN, United States, ${ }^{7}$ Department of Pediatrics, University of Cincinnati College of Medicine, Cincinnati, $\mathrm{OH}$, United States, ${ }^{8} \mathrm{Gl}$ obal Health Center, Cincinnati Children's Hospital Medical Center, Cincinnati, $\mathrm{OH}$, United States
\end{abstract}

Objectives: Newborn screening in the United States and Europe allows early identification of congenital disorders but does not yet exist in most low-resource settings, especially in sub-Saharan Africa. Newborn screening can identify multiple inherited hematological disorders, but feasibility and effectiveness for Africa are not fully determined.

Methods: Surplus dried blood spot collected in Central Malawi through the HIV Early Infant Diagnosis surveillance program were repurposed and tested by isoelectric focusing for sickle cell disease and trait. Additional genetic testing identified G6PD deficiency and alpha thalassemia.

Results: Testing of 10,529 cards revealed an overall sickle cell trait prevalence of $7.0 \%$ (range 3.9-9.7\% by district); 10 of 14 infants identified with sickle cell disease (prevalence $0.1 \%)$ were located and received care at a specialized clinic. Subsequent testing of 1,329 randomly selected cards identified alpha thalassemia trait in $45.7 \%$ of samples, and G6PD deficiency in $20.4 \%$ of males and $3.4 \%$ of females, with $29.0 \%$ of females as heterozygous carriers.

Conclusion: Inherited hematological disorders are common in Central Malawi; early identification through newborn screening can improve clinical outcomes and should be supported throughout Africa.

Keywords: newborn screening, sickle cell disease, sickle cell trait, alpha thalassemia, G6PD deficiency, Malawi 


\section{INTRODUCTION}

In high-income countries, newborn screening occurs for over 50 congenital health conditions, supported by government funding, public education, and trained health care workers [1]. However, in sub-Saharan Africa, newborn screening programs are limited in scope and may only screen for a single disease within restricted populations who have access to health care [2]. For conditions such as sickle cell disease (SCD), the global disparity in newborn screening neglects populations that are most at risk; $85 \%$ of SCD cases occur in Africa [3] where early-life mortality estimates range between 50 and $90 \%$, especially in areas where there is limited clinical awareness of signs and symptoms, and where SCD diagnosis and treatment are scant or nonexistent [4]. In some developed countries, newborn screening for SCD is included in formal recommendations and national guidelines [5,6]; these national newborn screening programs have been developed through pilot programs which have compiled enough evidence to show that newborn screening is necessary for better health outcomes [7]. In Africa, standardized guidelines are not available, but an effort has been made in recent years to report the results of ongoing programs and to increase international collaboration $[2,8]$, contributing to heightened awareness of SCD screening among decision makers in Ministries of Health.

In Malawi, the national prevalence of SCD was recently estimated to be $0.1 \%$ and the prevalence of sickle cell trait (SCT) to be $9.1 \%$ [9] with estimates varying by geographic area. Children in Malawi with SCD likely constitute a large proportion of deaths attributed to other leading causes of mortality such as malaria, anemia, acute respiratory infection, prematurity, bacteremia, and HIV/AIDS. The true burden of SCD is not known due to a lack of awareness and diagnostic testing, and small sample sizes limit the accuracy and generalizability of current and historical estimates. Since deaths due to SCD mostly occur in children under five years old, efforts to save lives must include early diagnosis and treatment. Many affected children are only diagnosed after they develop severe symptoms or may never reach a hospital setting before death; presumably, many die without ever having the proper diagnosis established.

In addition to SCD and SCT, $\alpha$-thalassemia and glucose-6phosphate dehydrogenase (G6PD) deficiency are inherited blood disorders that are common among Malawian children; a recent country-wide survey revealed that over $40 \%$ of children under five years have deletion of one or two a-globin genes ( $\alpha$-thalassemia trait) and $20 \%$ of males have G6PD deficiency [9]. Inherited hemoglobinopathies are associated with early death, as well as acute and chronic health conditions and loss of productivity [10]. However, no research has assessed the practicality of prospective newborn screening for SCD and other inherited blood disorders in Malawi, or demonstrated the feasibility of finding affected babies with subsequent linkage to clinical care $[9,11,12]$.

Malawi has a well-established regionalized HIV Early Infant Diagnosis (EID) program that conducts DNA and/or RNA PCR analysis on dried blood spots (DBS) collected within 6 weeks of birth from HIV-exposed infants born to HIV positive mothers [13]. The objective of this study was to repurpose existing DBS from EID programs to conduct the first ever regional SCD surveillance study in Malawi, to estimate the prevalence of SCD and SCT across the Central region. We explore associations between SCT, SCD, and malaria, and further identify G6PD deficiency and a-thalassemia trait among our study population using genetic testing methods. Determining the prevalence and distribution of inherited blood disorders represents the first step toward designing and targeting interventions to screen, diagnose, and manage these diseases in at-risk populations.

\section{METHODS}

\section{Study Design and Population}

The Central region of Malawi is home to 7.5 million people, representing $43 \%$ of the country's total population. As part of the Malawi EID program, HIV-exposed infants are tested for HIV at their first postnatal visit, usually at approximately 6 weeks of age, as part of the prevention of mother-to-child transmission program. The current study used existing, surplus DBS that were collected from children $<24$ months of age and tested for $\mathrm{HIV}$ at the Kamuzu Central Hospital (KCH), Partners in Hope, and Mzimba District Hospital Molecular Laboratories between May 2018 and December 2018. The study was approved by the National Health Sciences Research Committee at the Malawi Ministry of Health, the University of North Carolina at Chapel Hill (UNC) Institutional Review Board, and the Cincinnati Children's Hospital Institutional Review Board.

Most SCD testing and care in the Central region takes place at $\mathrm{KCH}$, a 1,000-bed, public tertiary care hospital operated by the Malawi Ministry of Health that serves a population of nearly 4 million people. A SCD clinic is held at $\mathrm{KCH}$ one day each week where approximately 500 children with SCD are enrolled in treatment and follow-up [14].

\section{Sample Collection}

Clinicians, nurses, and laboratory managers from nine district hospitals, one tertiary hospital, and one private hospital in the Central Region were trained with instructions and educational materials to inform EID families that their children would be tested for SCD alongside HIV and notified and referred to clinical services if results were SCD positive. Parents of children with SCT were not notified, as those with a single abnormal $\mathrm{HbS}$ gene are largely asymptomatic carriers and are relatively protected from malaria infection, compared to normal children [15]. Five laboratory technicians completed on-site training for isoelectric focusing (IEF) operation and interpretation throughout the course of the study, and 33 selected clinicians and nurses from 11 health facilities in the catchment area were trained in SCD management for positive cases.

To test for HIV in the EID program, several drops of whole blood were collected from the infant's heel onto Whatman 903 DBS protein saver filter paper. DBS cards were labeled with the date of collection and a unique identifying number, and demographic information was collected into an electronic data system. The specimens were air dried for a minimum of $4 \mathrm{~h}$ at room temperature. DBS from local health facilities were sent to 
dispatch hubs, where they were collated and forwarded to one of the three molecular laboratories participating in the study. Once DBS were tested for HIV, the cards were then sent to the UNC Project laboratory and repurposed for SCD testing. Each infant was linked to his/her accompanying DBS sample using unique identifying numbers and the demographic data from the EID electronic laboratory record.

\section{Laboratory Procedures}

A small $(\sim 3 \mathrm{~mm})$ punch was removed from each DBS for the purpose of hemoglobin analysis using IEF gel analysis (PerkinElmer, Inc.) to test for $\mathrm{HbS}$ and other variant hemoglobins. Each punch was placed into a 96-well plate, followed by elution of hemoglobin using Resolve systems $\mathrm{Hb}$ Elution solution and electrophoresis using pre-cast agarose gels. IEF equipment and supplies were provided by PerkinElmer, Inc., and training was conducted by experienced technicians from Cincinnati Children's Hospital. IEF gel bands were read and interpreted by trained laboratory technicians and reviewed by supervisory personnel. Children with SCD were traced by obtaining a parent's contact information through registers at the testing health facilities and children were subsequently referred for management and care at $\mathrm{KCH}$. Further testing of family members was not conducted.

After hemoglobin analysis, a subset of samples was sent to Cincinnati Children's Hospital for testing of G6PD deficiency and a-thalassemia trait. The subset included all SCD cases and a random selection of up to 50 SCT and 50 normal samples within each stratum of sex and district. Samples were shipped on dry ice and kept frozen at $-80^{\circ} \mathrm{C}$ until use. Genomic DNA analysis was performed as previously described [16,17] with accurate PCRbased techniques used to identify the presence of one-gene or two-gene deletional $\alpha$-thalassemia (3.7 $\mathrm{kb}$ rightward deletion), as well as the presence of the G6PD $\mathrm{A}^{-}$variant that is common in African settings.

\section{Statistical Analysis}

Prevalence measures were calculated by dividing SCD, SCT, a-thalassemia trait, and G6PD deficiency case numbers over the total sample size within each district. Significance tests were computed using Pearson's chi-square tests at $\alpha=0.05$. Historical malaria prevalence estimates, (Plasmodium falciparum in children ages 1-10 years) were taken from modeled population-based, community-level data collected from 1970 to 2001 at 73 survey locations across Malawi [18].

All analyses were conducted in SAS 9.4 (SAS Institute Inc., Cary, NC, United States), R 3.5.1 (R Foundation for Statistical Computing, Vienna, Austria), and QGIS 3.4.0 (Open Source Geospatial Foundation Project).

\section{RESULTS}

A total of 10,529 DBS samples were analyzed and linked to clinical and demographic data. Samples were evenly distributed by sex with 5,177 (49.2\%) female and 5,082 (48.3\%) male participants, and $270(2.5 \%)$ with unknown sex. Among the

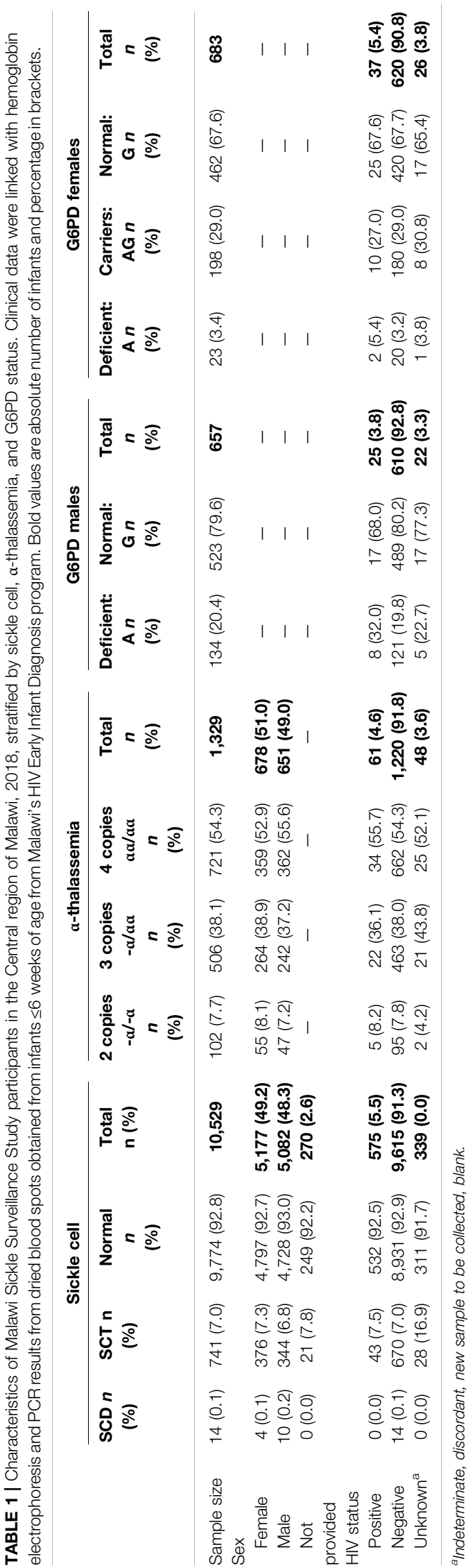



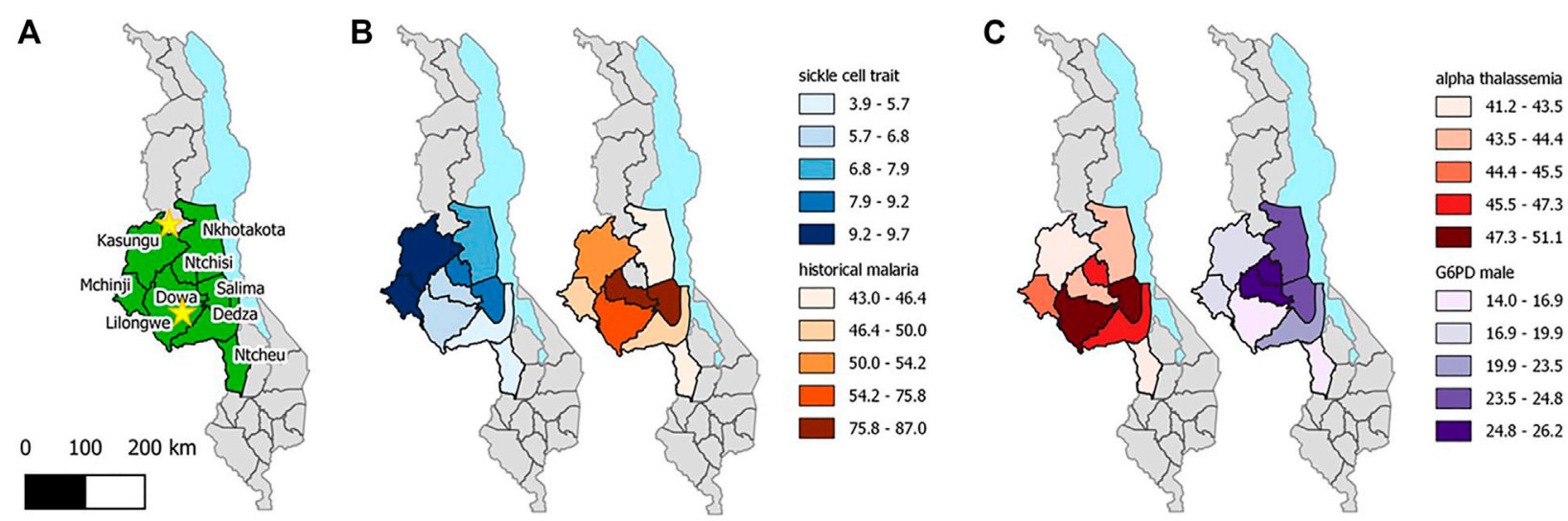

FIGURE 1 | Malawi Sickle Surveillance Study prevalence estimates for sickle cell trait, historical malaria, $\alpha$-thalassemia trait (- $\alpha$-- $\alpha$ or - $\alpha / a \alpha)$, G6PD deficiency in males, and G6PD deficiency/carrier status in females by district in the Central region of Malawi, 2018. Historical malaria prevalence estimates, (Plasmodium falciparum in children ages 1-10) are taken from data from 1970 to 2001 at 73 survey locations across Malawi [18]. Stars represent the location of Early Infant Diagnosis laboratory collaborators (Partners in Hope and Kamuzu Central Hospital in Lilongwe and Mzimba District Hospital in the North).

10,529 DBS, $14(0.1 \%)$ were classified as SCD, $741(7.0 \%)$ as SCT, and $9,774(92.8 \%)$ as normal (Table 1). There were no significant differences in the prevalence of either SCD or SCT by sex. The vast majority $(9,615 / 10,529,91.3 \%)$ of samples were HIV negative and all 14 SCD samples were HIV negative. Of the 1,329 samples tested for $\alpha$-thalassemia, 506 (38.1\%) had deletion of one $\alpha$-globin gene, $-\alpha / \alpha \alpha$, and $102(7.7 \%)$ had deletion of two $\alpha$-globin genes, $-\alpha /-\alpha$. About one-fifth of the males $(134 / 657,20.4 \%)$ were G6PD deficient, as were a smaller number $(23 / 683,3.4 \%)$ of females. Almost one-third of females (198/683, 29.0\%) were heterozygous carriers of G6PD deficiency.

SCT prevalence was highest in the Northwest and lowest in the Southern part of Central region, ranging from 3.9\% in Dedza to $9.7 \%$ in Kasungu (Figure 1). The highest SCT prevalence districts did not correspond closely with districts reporting the highest malaria prevalence in children, using historical data. However, malaria data were only available within the last few decades, limiting the extent of inference to selective genetic pressures. Of the 14 SCD cases, 12 were from Lilongwe ( $0.3 \%$ of Lilongwe samples), one was from Mchinji, and one from Ntcheu (Table 2). The prevalence of $\alpha$-thalassemia trait $(-\alpha /-\alpha$ or $-\alpha / \alpha \alpha)$ ranged from $41.2 \%(56 / 136)$ in Ntcheu to $51.1 \%$ (94/184) in Salima. G6PD deficiency prevalence among males ranged from $14.0 \%(15 / 107)$ in Lilongwe to $26.2 \%(16 / 61)$ in Dowa. G6PD deficiency or G6PD heterozygous carrier status was lowest in Ntchisi $(13 / 57 ; 22.8 \%)$ and highest in Salima (42/ 92, 45.7\%).

The presence of SCT appeared to be inversely associated with G6PD trait in males; $22.1 \%$ (97/439) of male infants without SCT had G6PD deficiency, while 16.7\% (35/209) of SCT males were G6PD deficient, however, these estimates did not reach statistical significance $(p=0.1)$ (Table 3).

Of the 14 cases of SCD, 10 babies were successfully traced and brought for management and care at the KCH SCD Clinic. This included verification of disease by repeat isoelectric hemoglobin electrophoresis for SCD, initiation of folic acid supplements, penicillin prophylaxis, pneumococcal vaccination, malaria prophylaxis with sulfadoxine-pyrimethamine, and the opportunity to receive disease-modifying treatment with hydroxyurea. The four remaining cases of SCD were unable to be traced; one relocated to Blantyre, and three could not be reached due to a missing register $\log$ at one of the clinics that contained the patients' contact information.

\section{DISCUSSION}

Newborn screening for SCD and other hemoglobin disorders is now universal in the United States, with excellent results and outcomes [19]. Despite infrastructure limitations, small urban newborn screening programs for SCD have proven to be feasible in Ghana [20], Benin [21], Nigeria [22], and the Democratic Republic of Congo [23]. Comparable to resource-rich countries, early diagnosis followed by active management of affected children has also shown decreased mortality in Benin and Jamaica [24]. Pilot data from the Republic of Angola documented a high SCD incidence, with successful location and retrieval of affected babies allowing initiation of early lifesaving interventions including penicillin prophylaxis, pneumococcal vaccines, insecticide-treated bed nets, and parental education [25]. Hydroxyurea has recently been shown to have efficacy for children with SCD living in sub-Saharan Africa [26,27], and should also become part of the clinical management of children identified with SCD through newborn screening programs.

We documented the prevalence of inherited hematological disorders in the Central region as follows: $0.1 \%$ SCD, $7.0 \%$ SCT, $45.7 \%$ a-thalassemia trait, $20.4 \%$ G6PD deficiency in males, and $29.0 \%$ G6PD female carriers. Within the region, SCT prevalence varied by district, ranging from to $3.9-9.7 \%$, with the highest prevalence on the western border with Zambia and the southern border with Mozambique. Variation within the region is similar to that observed in Uganda, where the prevalence of SCT varied 3-5 fold across the country [28]. 
TABLE 2 | Prevalence of inherited hematological disorders in the Malawi Sickle Surveillance Study, stratified by district in the Central region of Malawi, 2018. Historical malaria prevalence estimates, (Plasmodium falciparum in children ages 1-10) are taken from data from 1970 to 2001 at 73 survey locations across Malawi [18]. Bold values are absolute number of infants and percentage in brackets.

\begin{tabular}{|c|c|c|c|c|c|c|c|c|c|c|c|c|c|c|c|c|c|}
\hline & \multirow[b]{2}{*}{ District } & \multirow{2}{*}{$\begin{array}{l}\frac{\text { Malaria }}{\text { Prevalence }} \\
1970-2001\end{array}$} & \multicolumn{4}{|c|}{ Sickle cell } & \multicolumn{4}{|c|}{$\alpha$-thalassemia ${ }^{a}$} & \multicolumn{3}{|c|}{ G6PD males ${ }^{\mathrm{b}}$} & \multicolumn{4}{|c|}{ G6PD females ${ }^{c}$} \\
\hline & & & $\begin{array}{l}\operatorname{SCD} n \\
(\%)\end{array}$ & $\begin{array}{l}\text { SCT } n \\
(\%)\end{array}$ & $\begin{array}{c}\text { Normal } \\
n(\%)\end{array}$ & $\begin{array}{l}\text { Total } \\
n(\%)\end{array}$ & $\begin{array}{c}2 \text { copies } \\
-\alpha /-\alpha \\
n(\%)\end{array}$ & $\begin{array}{c}3 \text { copies } \\
-a / a a \\
n(\%)\end{array}$ & $\begin{array}{c}4 \text { copies } \\
\text { a } / \text { aa } \\
n(\%)\end{array}$ & $\begin{array}{l}\text { Total } \\
n(\%)\end{array}$ & $\begin{array}{l}\text { Deficient: } \\
\text { A } \boldsymbol{n}(\%)\end{array}$ & $\begin{array}{l}\text { Normal: } \\
G \boldsymbol{n}(\%)\end{array}$ & $\begin{array}{l}\text { Total } \\
n(\%)\end{array}$ & $\begin{array}{l}\text { Deficient: } \\
\text { A } \boldsymbol{n}(\%)\end{array}$ & $\begin{array}{l}\text { Carriers: } \\
\text { AG } n(\%)\end{array}$ & $\begin{array}{l}\text { Normal: } \\
\mathbf{G} \boldsymbol{n}(\%)\end{array}$ & $\begin{array}{l}\text { Total } \\
n(\%)\end{array}$ \\
\hline 1 & Dedza & 0.50 & $0(0.0)$ & $28(3.9)$ & $684(96.1)$ & $712(6.8)$ & $12(9.6)$ & $45(36.0)$ & $68(54.4)$ & $125(9.4)$ & $12(21.4)$ & $44(78.6)$ & $56(8.5)$ & $1(1.4)$ & $17(24.6)$ & $51(73.9)$ & $69(10.1)$ \\
\hline 2 & Dowa & 0.87 & $0(0.0)$ & $24(6.6)$ & $341(93.4)$ & $365(3.5)$ & $6(5.0)$ & $46(38.7)$ & $67(56.3)$ & $119(9.0)$ & $16(26.2)$ & $45(73.8)$ & $61(9.3)$ & $2(3.4)$ & $13(22.0)$ & $44(74.6)$ & $59(8.6)$ \\
\hline 3 & Kasungu & 0.53 & $0(0.0)$ & $70(9.7)$ & $650(90.3)$ & $720(6.8)$ & $14(9.6)$ & $49(33.6)$ & $83(56.8)$ & $146(11.0)$ & $12(17.6)$ & $56(82.4)$ & 68 (10.4) & $4(5.1)$ & $17(21.5)$ & $58(73.4)$ & 79 (11.6) \\
\hline 4 & Lilongwe & 0.59 & $12(0.3)$ & $318(6.7)$ & 4,427 (93.1) & 4,757 (45.2) & $18(8.6)$ & $82(39.2)$ & $109(52.2)$ & $209(15.7)$ & $15(14.0)$ & $92(86.0)$ & 107 (16.3) & $3(2.9)$ & $29(28.2)$ & $71(68.9)$ & $103(15.1)$ \\
\hline 5 & Mchinji & 0.50 & $1(0.1)$ & $110(9.6)$ & $1,039(90.3)$ & 1,150 (10.9) & $14(7.6)$ & $69(37.5)$ & $101(54.9)$ & $184(13.8)$ & 17 (19.5) & 70 (80.5) & 87 (13.2) & $3(3.1)$ & $30(30.6)$ & $65(66.3)$ & 98 (14.3) \\
\hline 6 & Nkhotakota & 0.44 & $0(0.0)$ & $29(7.3)$ & $366(92.7)$ & $395(3.8)$ & $6(5.3)$ & $44(38.9)$ & $63(55.8)$ & $113(8.5)$ & $14(24.6)$ & $43(75.4)$ & $57(8.7)$ & $1(1.8)$ & $20(35.1)$ & $36(63.2)$ & $57(8.3)$ \\
\hline 7 & Ntcheu & 0.43 & $1(0.1)$ & $42(4.4)$ & 906 (95.5) & $949(9.0)$ & $9(6.6)$ & $47(34.6)$ & $80(58.8)$ & $136(10.2)$ & $11(15.9)$ & $58(84.1)$ & $69(10.5)$ & $2(2.9)$ & $24(34.8)$ & $43(62.3)$ & $69(10.1)$ \\
\hline 8 & Ntchisi & $N A$ & $0(0.0)$ & $14(8.9)$ & $143(91.1)$ & $157(1.5)$ & $11(9.7)$ & $42(37.2)$ & $60(53.1)$ & $113(8.5)$ & $14(25.0)$ & $42(75.0)$ & $56(8.5)$ & $1(1.8)$ & $12(21.1)$ & $44(77.2)$ & $57(8.3)$ \\
\hline 9 & Salima & 0.87 & $0(0.0)$ & $106(8.0)$ & $1,218(92.0)$ & $1,324(12.6)$ & $12(6.5)$ & $82(44.6)$ & $90(48.9)$ & $184(13.8)$ & $23(24.0)$ & $73(76.0)$ & 96 (14.6) & $6(6.5)$ & $36(39.1)$ & $50(54.3)$ & 92 (13.5) \\
\hline
\end{tabular}

${ }^{b}$ tested $=657$

${ }^{c} \mathrm{n}$ tested $=683$

TABLE 3 | Sickle cell disease, sickle cell trait, $\boldsymbol{\alpha}$-thalassemia deficiency, and G6PD deficiency and carrier status prevalence estimates among Malawi Sickle Surveillance study participants, 2018, stratified by genotype.

\begin{tabular}{|c|c|c|c|c|c|c|c|c|c|c|c|c|}
\hline & & \multicolumn{4}{|c|}{$\alpha$-thalassemia ${ }^{a}$} & \multicolumn{3}{|c|}{ G6PD males ${ }^{b}$} & \multicolumn{4}{|c|}{ G6PD females ${ }^{c}$} \\
\hline & & $\begin{array}{c}2 \text { copies } \\
-\alpha /-\alpha \\
n(\%)\end{array}$ & $\begin{array}{c}3 \text { copies } \\
-\alpha / \alpha \alpha \\
n(\%)\end{array}$ & $\begin{array}{c}4 \text { copies } \\
\alpha \alpha / \alpha \alpha \\
n(\%)\end{array}$ & $\begin{array}{l}\text { Total } \\
n(\%)\end{array}$ & $\begin{array}{c}\text { Deficient: } \\
\text { A } n(\%)\end{array}$ & $\begin{array}{l}\text { Normal: } \\
\text { G } n(\%)\end{array}$ & $\begin{array}{l}\text { Total } \\
n(\%)\end{array}$ & $\begin{array}{c}\text { Deficient: } \\
\text { A } n(\%)\end{array}$ & $\begin{array}{c}\text { Carrier: } \\
\text { AG } n(\%)\end{array}$ & $\begin{array}{l}\text { Normal: } \\
\text { G } n(\%)\end{array}$ & $\begin{array}{l}\text { Total } \\
n(\%)\end{array}$ \\
\hline \multirow[t]{3}{*}{ Sickle cell } & Disease & $1(7.7)$ & $3(23.1)$ & 9 (69.2) & $13(1.0)$ & 2 (22.2) & 7 (77.8) & $9(1.4)$ & - & - & $4(100.0)$ & $4(0.6)$ \\
\hline & Trait & $32(7.3)$ & $167(38.2)$ & $238(54.5)$ & 437 (32.9) & 35 (16.7) & 174 (83.3) & 209 (31.8) & $9(3.8)$ & $68(29.1)$ & $157(67.1)$ & 234 \\
\hline & Normal & $69(7.8)$ & 336 (38.2) & 474 (53.9) & 879 (66.1) & 97 (22.1) & $342(77.9)$ & $439(66.8)$ & $14(3.1)$ & $130(29.2)$ & 301 (67.6) & $445(65.2$ \\
\hline \multirow[t]{4}{*}{$\alpha$-thalassemia } & $-\alpha /-\alpha$ & - & - & - & - & 9 (19.1) & 38 (80.9) & 47 (7.2) & $3(5.5)$ & 17 (30.9) & 35 (63.6) & $55(8.1)$ \\
\hline & $-\alpha / \alpha \alpha$ & - & - & - & - & 45 (18.6) & $197(81.4)$ & 242 (36.8) & $10(3.8)$ & 75 (28.4) & $179(67.8)$ & 264 (38.7 \\
\hline & $\alpha \alpha / \alpha \alpha$ & - & - & - & - & 80 (22.1) & $282(77.9)$ & $362(55.1)$ & $10(2.8)$ & $102(28.4)$ & $247(68.8)$ & $359(52.6$ \\
\hline & No score & - & - & - & - & - & $6(100.0)$ & $6(0.9)$ & - & $4(80.0)$ & $1(20.0)$ & $5(0.7)$ \\
\hline
\end{tabular}

$a_{\mathrm{n}}$ tested $=1,329$

$b_{n}$ tested $=657$.

${ }^{c} \mathrm{n}$ tested $=683$. 
The prevalence of SCD among our study population, $0.1 \%$, is within the lower bound of prior estimates found among infants and preschool children in Malawi, which range from 0.04 to $2.5 \%$ $[9,11,12]$. Our SCT prevalence of $7.0 \%$ is slightly lower than that the $9.1 \%$ SCT figure recently cited in a national secondary analysis of children under the age of five in Malawi, and prevalence of $\alpha$-thalassemia and G6PD deficiency were similar [9]. The burden of SCD in Malawi has been underappreciated as a source of childhood morbidity and mortality, but is also lower than estimates found in the neighboring countries of Tanzania $(0.6 \%)$ and Zambia (0.9\%) [2,29]. However, prevalence measures in Tanzania are also known to vary geographically; preliminary data using EID samples from Northern Tanzania found a $20.8 \%$ prevalence of SCT [30], while lower estimates of SCT down to 9.6\% have been found in areas in and around Dar es Salaam [31].

a-thalassemia trait in our study cohort also varied geographically, from $41.2 \%$ to $51.1 \%$ by district, confirming a high allele frequency of the $3.7 \mathrm{~kb}$ rightward deletion in Eastern Africa. A prior analysis of Malawian children tested in a smaller country-wide anemia survey [9] documented a $43 \%$ prevalence of $\alpha$ - thalassemia trait $(33 \%-\alpha / \alpha \alpha$ and $10 \%-\alpha /-\alpha)$, which is similar to our findings in the Central region. We noted substantial variation within the region with higher prevalence in the south, analogous to observations in Uganda where the prevalence of $\alpha$-thalassemia trait increased toward the eastern part of the country [17].

Similarly, the prevalence of G6PD deficiency was high in the Central region of Malawi, with one-fifth of males affected and almost one-third of females (29.0\% carriers, $3.4 \%$ affected). As with the other hematological disorders, the prevalence varied across the Central region, with district prevalence ranging from $14.0 \%$ to $26.2 \%$ among males. The prevalence of G6PD deficiency is higher than published values for Uganda, where $14 \%$ of males were affected overall, and an increasing prevalence toward the southern portion of the country [17].

Decades ago, Haldane posited his malaria hypothesis that maintaining a high frequency of genetic hematological disorders is the advantage gained by the affected individual for malaria survival [32]. Especially for SCT, varying geographical differences relates to the distribution of $P$. falciparum malaria; persons with SCT have been shown to be less likely to acquire malaria infection and even less likely to die of severe malaria [33-35]. However, the SCT prevalence within the Central region of Malawi did not correlate with historical patterns of malaria prevalence from 1970 to 2001 (Figure 1), perhaps because of advances in malaria diagnosis and treatment; strong genetic selection pressure has likely been superseded by migration patterns and malaria control measures over the past 20 years [36]. A smaller national survey in Malawi showed similar results; SCT prevalence by region did not align with malaria prevalence either by rapid diagnostic test or by self-report of recent infection [9].

Importantly, the prevalence of these three hematological conditions that confer protection against malaria were not well correlated across the Central region of Malawi, and the highest prevalence of each trait was found in different districts. This lack of correlated prevalence reflects the tendency for individual protective traits to negate the effects of another. Such negative epistasis has been reported between SCT and $\alpha$-thalassemia in
Kenya [37], and between SCT and G6PD deficiency in Mali [38], with no additive protection and even loss of protection against malaria infection. To our knowledge, this is the first report of all three protective traits plotted with the same geographical distribution, which supports the concept of negative epistasis for malaria in Central Malawi.

a-HIV EID programs, which exist in all 46 PEPFAR countries, should be considered an available and feasible mechanism for introducing newborn screening to determine SCD prevalence, while simultaneously acting as a physical infrastructure platform for treatment services. SCD is a lifelong chronic condition requiring consistent treatment with penicillin, hydroxyurea, and intermittent acute care for severe events such as blood transfusions, and using existing systems such as immunization and HIV early care programs can be a sustainable and essential way to retain young adults and children in care [2,39]. While screening is the first step in understanding the burden of disease, treatment is necessary to reduce morbidity and mortality from SCD. A recent study reporting on baseline clinical and laboratory characteristics of children confirmed with SCD at KCH in Central Malawi found that patients had substantial morbidity, with a large percent reporting histories of anemia (71.8\%), jaundice (52.1\%), joint pain (56.4\%), and pain episodes (49.6\%) [40]. A remarkable $74.4 \%$ had received at least one previous blood transfusion, which stresses the need for improving and standardizing approaches to transfusion therapy for children with SCD, especially in a setting with limited blood supply. Implementation of hydroxyurea has already been shown to be safe and effective, with clinical benefits for high-risk children with SCD in our setting [14]. Currently, $\mathrm{KCH}$ is the only clinic in the Central region that has specific SCD management, and transportation and distance are barriers to patient referral. Education for district clinicians on SCD treatment and management are key components of a scale-up of a national screening program, incorporating training to identify and test anemic hospitalized children to locate those at highrisk of underlying SCD.

A major strength of this study is the use of existing DBS and a centralized laboratory testing system, demonstrating a mechanism that could be scaled-up to create a national testing program. Additionally, this is the first regional SCD surveillance study in Malawi, collecting samples from all districts in the Central region, and showing variation in the prevalence of SCD, SCT, a-thalassemia trait, and G6PD deficiency over a broad geographical area. Distribution patterns of genetic factors of disease provide justification for improved laboratory capacity and for the expansion of both newborn screening programs and SCD diagnosis and treatment infrastructure. A broader scale-up of our methods could successfully connect infants to care, potentially leading to better health outcomes and lower mortality.

This study was limited by the small number of SCD cases. Testing of over 10,000 samples only yielded 14 SCD cases, however our sample size is much larger than previous surveillance studies showing the effectiveness of newborn screening programs elsewhere in sub-Saharan Africa [31,41]. Limitations to generalizability in a broader population could include selection bias stemming from our sampling of HIVexposed infants through Malawi's EID program. Mothers may 
be more likely to bring infants to be tested who are sicker, whether from HIV or SCD related symptoms. Despite this potential bias, EID programs are a good starting point for SCD screening, given the hypothesized increased morbidity of SCD in HIV infected infants [17]. Children with SCD were followed up, but parents of children with other inherited blood disorders were not contacted, as $\alpha$-thalassemia trait does not require specific medical intervention, and primaquine, the main source of morbidity for G6PD deficient children, is not commonly used in Malawi.

A final consideration relates to the burden of disease and the likelihood of creating a feasible and cost-effective newborn screening programs in sub-Saharan Africa. The Central region of Malawi has an approximate crude birth rate of 32.5 births per 1,000 population, with an estimated 244,600 children born to mothers in the Central region during the 12 months prior to the 2018 census [42]. Using the disease rates detected in our study, we would expect approximately 325 children in the Central region to be born each year with SCD and 17,214 children to be born each year with SCT. The high prevalence of the HbS allele in subSaharan Africa, where overall under-5 mortality from other causes is improving, suggests that the relative contribution of SCD to under-5 mortality is likely to increase significantly and steadily over the coming years [43]. Affected babies with SCD, who would previously have died early in life from other causes, may now be surviving long enough to present for diagnosis and develop serious morbidity that requires care and treatment [44]. The results from our study indicate that developing a newborn screening program is feasible in Malawi, both to conduct disease surveillance, and to locate children with SCD and integrate them into care. Newborn screening is the first step to improving existing care and treatment programs to incorporate SCD management based on the geographic burden of disease, targeting highly affected districts for introduction of an integrated community-based diagnosis, care, and treatment program.

\section{DATA AVAILABILITY STATEMENT}

The original contributions presented in the study are included in the article/supplementary material, further inquiries can be directed to the corresponding author.

\section{REFERENCES}

1. Therrell, BL, Padilla, CD, Loeber, JG, Kneisser, I, Saadallah, A, Borrajo, GJC, et al. Current Status of Newborn Screening Worldwide: 2015. Semin Perinatol (2015). 39:171-87. doi:10.1053/j.semperi.2015.03.002

2. Therrell, BL, Lloyd-Puryear, MA, Lloyd-Puryear, MA, Ohene-Frempong, K, Ware, RE, Padilla, CD, et al.Empowering Newborn Screening Programs in African Countries Through Establishment of an International Collaborative Effort. J Commun Genet (2020). 11:253-68. doi:10.1007/s12687-020-00463-7

3. Modell, B, and Darlison, M. Global Epidemiology of Haemoglobin Disorders and Derived Service Indicators. Bull World Health Organ (2008). 2008:480-7. doi:10.2471/blt.06.036673

4. Grosse, SD, Odame, I, Atrash, HK, Amendah, DD, Piel, FB, and Williams, TN. Sickle Cell Disease in Africa. Am J Prev Med (2011). 41:S398-S405. doi:10.1016/j.amepre.2011.09.013

\section{ETHICS STATEMENT}

The studies involving human participants were reviewed and approved by the Malawi National Health Science Research Committee at the Malawi Ministry of Health, The University of North Carolina at Chapel Hill (UNC) Institutional Review Board, The Cincinnati Children's Hospital Institutional Review Board. Written informed consent from the participants' legal guardian/next of kin was not required to participate in this study in accordance with the national legislation and the institutional requirements.

\section{AUTHOR CONTRIBUTIONS}

GT, TM, IH, and RW contributed to study conception and design. GT, PK, TH, ZT, NC, WK, TM, and AH contributed to data acquisition. HT performed the data analysis and GT, HT, $\mathrm{PK}, \mathrm{TH}, \mathrm{TM}, \mathrm{IH}$, and RW were involved in methodology decisions and data interpretation. GT, HT, and RW drafted the manuscript. All authors provided revisions and approval for submission.

\section{CONFLICT OF INTEREST}

The authors declare that the research was conducted in the absence of any commercial or financial relationships that could be construed as a potential conflict of interest.

\section{ACKNOWLEDGMENTS}

We thank our study participants, the Malawi Ministry of Health, the University of North Carolina (UNC) Project-Malawi community tracing team, and the Kamuzu Central Hospital, Mzimba District Hospital, Partners in Hope, and UNC Project laboratories. We thank Cincinnati Children's Hospital and PerkinElmer Inc. for equipment, reagents, supplies, training, and UNC Chapel Hill for financial support.

5. Lobitz, S, Telfer, P, Cela, E, Allaf, B, Angastiniotis, M, Backman Johansson, C, et al. Newborn Screening for Sickle Cell Disease in Europe: Recommendations From a Pan-European Consensus Conference. Br J Haematol (2018). 183(4): 648-60. doi:10.1111/bjh.15600

6. Yawn, BP, Buchanan, GR, Afenyi-Annan, AN, Ballas, SK, Hassell, KL, James, AH, et al. Management of Sickle Cell Disease: Summary of the 2014 EvidenceBased Report by Expert Panel Members. JAMA (2014). 312(10):1033-48. doi:10.1001/jama.2014.10517

7. Colombatti, R, Martella, M, Cattaneo, L, Viola, G, Cappellari, A, Bergamo, C, et al. Results of a Multicenter Universal Newborn Screening Program for Sickle Cell Disease in Italy: A Call to Action. Pediatr Blood Cancer (2019). 66(5): e27657. doi:10.1002/pbc. 27657

8. Hernandez, AG, Kiyaga, C, Howard, TA, Ssewanyana, I, Ndeezi, G, Aceng, JR, et al. Trends in Sickle Cell Trait and Disease Screening in the Republic of Uganda, 2014-2019. Trop Med Int Health (2020). 26(1):23-32. doi:10.1111/ tmi.13506 
9. McGann, PT, Williams, AM, Ellis, G, McElhinney, KE, Romano, L, Woodall, J, et al. Prevalence of Inherited Blood Disorders and Associations with Malaria and Anemia in Malawian Children. Blood Adv (2018). 2:3035-44. doi:10.1182/ bloodadvances.2018023069

10. Weatherall, D, Akinyanju, O, and Fucharoen, S. Inherited Disorders of Hemoglobin. In: Jamison, DT, Breman, JG, and Measham, AR, editors. Disease Control Priorities in Developing Countries. 2nd ed. Washington, DC: The International Bank for Reconstruction and Development/The World Bank (2006).

11. Brabin, BJ, Prinsen-Geerligs, PD, Verhoeff, FH, Fletcher, KA, Chimsuku, LHE, Ngwira, BM, et al. Haematological Profiles of the People of Rural Southern Malawi: An Overview. Ann Trop Med Parasitol (2004). 98:71-83. doi:10.1179/ 000349804225003055

12. Calis, JCJ, Phiri, KS, Faragher, EB, Brabin, BJ, Bates, I, Cuevas, LE, et al. Severe Anemia in Malawian Children. N Engl J Med (2008). 358:888-99. doi:10.1056/ NEJMoa072727

13. World Health Organization. Consolidated Guidelines on the Use of Antiretroviral Drugs for Treating and Preventing HIV Infection. Geneva, Switzerland: World Health Organization (2016).

14. Mvalo, T, Topazian, HM, Kamthunzi, P, Chen, JS, Kambalame, I, Mafunga, P, et al. Real-world Experience Using Hydroxyurea in Children With Sickle Cell Disease in Lilongwe, Malawi. Pediatr Blood Cancer (2019). 66:e27954. doi:10.1002/pbc.27954

15. Serjeant, GR. The Natural History of Sickle Cell Disease. Cold Spring Harbor Perspect Med (2013). 3:a011783. doi:10.1101/cshperspect.a011783

16. McGann, PT, Williams, TN, Olupot-Olupot, P, Tomlinson, GA, Lane, A, Luís Reis da Fonseca, J, et al. Realizing Effectiveness Across Continents With Hydroxyurea: Enrollment and Baseline Characteristics of the Multicenter REACH Study in Sub-Saharan Africa. Am J Hematol (2018). 93:537-45. doi:10.1002/ajh.25034

17. Kiyaga, C, Hernandez, AG, Ssewanyana, I, Schaefer, BA, McElhinney, KE, Ndeezi, G, et al. Sickle Cell Screening in Uganda: High burden, Human Immunodeficiency Virus Comorbidity, and Genetic Modifiers. Pediatr Blood Cancer (2019). 66:e27807. doi:10.1002/pbc.27807

18. Kazembe, LN, Kleinschmidt, I, Holtz, TH, and Sharp, BL. Spatial Analysis and Mapping of Malaria Risk in Malawi Using point-referenced Prevalence of Infection Data. Int J Health Geogr (2006). 5:41. doi:10.1186/1476-072X-5-41

19. Therrell, BL, Lloyd-Puryear, MA, Eckman, JR, and Mann, MY. Newborn Screening for Sickle Cell Diseases in the United States: A Review of Data Spanning 2 Decades. Semin Perinatol (2015). 39:238-51. doi:10.1053/ j.semperi.2015.03.008

20. Ohene-Frempong, K, Oduro, J, Tetteh, H, and Nkrumah, F. Screening Newborns for Sickle Cell Disease in Ghana. Pediatrics (2008). 121:S120. doi:10.1542/peds.2007-2022uuu

21. Rahimy, MC, Gangbo, A, Ahouignan, G, and Alihonou, E. Newborn Screening for Sickle Cell Disease in the Republic of Benin. J Clin Pathol (2009). 62:46-8. doi:10.1136/jcp.2008.059113

22. Odunvbun, ME, Okolo, AA, and Rahimy, CM. Newborn Screening for Sickle Cell Disease in a Nigerian Hospital. Public Health (2008). 122:1111-6. doi:10.1016/j.puhe.2008.01.008

23. Tshilolo, L, Aissi, LM, Lukusa, D, Kinsiama, C, Wembonyama, S, Gulbis, B, et al. Neonatal Screening for Sickle Cell Anaemia in the Democratic Republic of the Congo: Experience From a Pioneer Project on 31204 Newborns. J Clin Pathol (2009). 62:35-8. doi:10.1136/jcp.2008.058958

24. Lee, A, Thomas, P, Cupidore, L, Serjeant, B, and Serjeant, G. Improved Survival in Homozygous Sickle Cell Disease: Lessons From a Cohort Study. BMJ (1995). 311:1600-2. doi:10.1136/bmj.311.7020.1600

25. Mcgann, PT, Ferris, MG, Ramamurthy, U, Santos, B, de Oliveira, V, and Bernardino, LA Prospective Newborn Screening and Treatment Program for Sickle Cell Anemia in Luanda, Angola. Am J Hematol (2013). 88:984-9. doi:10.1002/ajh.23578

26. Tshilolo, L, Tomlinson, G, Williams, TN, Santos, B, Olupot-Olupot, P, Lane, A, et al. Hydroxyurea for Children With Sickle Cell Anemia in Sub-Saharan Africa. N Engl J Med (2019). 380:121-31. doi:10.1056/NEJMoa1813598

27. John, CC, Opoka, RO, Latham, TS, Hume, HA, Nabaggala, C, Kasirye, P, et al. Hydroxyurea Dose Escalation for Sickle Cell Anemia in Sub-Saharan Africa. N Engl J Med (2020). 382:2524-33. doi:10.1056/NEJMoa2000146
28. Ndeezi, G, Kiyaga, C, Hernandez, AG, Munube, D, Howard, TA, Ssewanyana, I, et al. Burden of Sickle Cell Trait and Disease in the Uganda Sickle Surveillance Study (US3): a Cross-Sectional Study. Lancet Glob Health (2016). 4:e195-e200. doi:10.1016/S2214-109X(15)00288-0

29. Piel, FB, Hay, SI, Gupta, S, Weatherall, DJ, and Williams, TN. Global Burden of Sickle Cell Anaemia in Children Under Five, 2010-2050: Modelling Based on Demographics, Excess Mortality, and Interventions. PLoS Med (2013). 10: e1001484. doi:10.1371/journal.pmed.1001484

30. Ambrose, EE, Smart, LR, Hokororo, A, Charles, M, Beyanga, M, Hernandez, AG, et al. Prevalence and Mapping of Sickle Cell Disease in Northwestern $\begin{array}{llll}\text { Tanzania. Blood } A d v & \text { (2017). } & 1: 26-8 . & \text { doi:10.1182/ }\end{array}$ bloodadvances.2017gs101607

31. Nkya, S, Mtei, L, Soka, D, Mdai, V, Mwakale, PB, Mrosso, P, et al. Newborn Screening for Sickle Cell Disease: An Innovative Pilot Program to Improve Child Survival in Dar es Salaam, Tanzania. Int Health (2019). 11:589-95. doi:10.1093/inthealth/ihz028

32. Haldane, JBS. The Rate of Mutation of Human Genes. Hereditas (1949). 35 267-73. doi:10.1111/j.1601-5223.1949.tb03339.x

33. Piel, FB, Patil, AP, Howes, RE, Nyangiri, OA, Gething, PW, Williams, TN, et al. Global Distribution of the Sickle Cell Gene and Geographical Confirmation of the Malaria Hypothesis. Nat Commun (2010). 1:1-7. doi:10.1038/ ncomms 1104

34. Thoreson, CK, O'Connor, MY, Ricks, M, Chung, ST, and Sumner, AE. Sickle Cell Trait from a Metabolic, Renal, and Vascular Perspective: Linking History, Knowledge, and Health. J Racial Ethn Health Disparities (2015). 2:330-5. doi:10.1007/s40615-014-0077-4

35. Naik, RP, and Haywood, C. Sickle Cell Trait Diagnosis: Clinical and Social Implications. Hematology (2015). 2015:160-7. doi:10.1182/asheducation2015.1.160

36. Mathanga, DP, Walker, ED, Wilson, ML, Ali, D, Taylor, TE, and Laufer, MK. Malaria Control in Malawi: Current Status and Directions for the Future. Acta Tropica (2012). 121:212-7. doi:10.1016/j.actatropica.2011.06.017

37. Williams, TN, Mwangi, TW, Wambua, S, Peto, TEA, Weatherall, DJ, Gupta, S, et al. Negative Epistasis Between the Malaria-Protective Effects of a+-Thalassemia and the Sickle Cell Trait. Nat Genet (2005). 37:1253-7. doi:10.1038/ng1660

38. Guindo, A, Traore, K, Diakite, $S$, Wellems, TE, Doumbo, OK, and Diallo, DA. An Evaluation of Concurrent G6PD (A-) Deficiency and Sickle Cell Trait in Malian Populations of Children With Severe or Uncomplicated P. falciparum Malaria. Am J Hematol (2011). 86:795-6. doi:10.1002/ajh.22093

39. McGann, PT, Hernandez, AG, and Ware, RE. Sickle Cell Anemia in Subsaharan Africa: Advancing the Clinical Paradigm Through Partnerships and Research. Blood (2017). 129:155-61. doi:10.1182/blood-2016-09-702324

40. Heimlich, JB, Chipoka, G, Kamthunzi, P, Krysiak, R, Majawa, Y, Mafunga, P, et al. Establishing Sickle Cell Diagnostics and Characterizing a Paediatric Sickle Cell Disease Cohort in Malawi. Br J Haematol (2016). 174:325-9. doi:10.1111/ bjh. 13769

41. Tshilolo, L, Kafando, E, Sawadogo, M, Cotton, F, Vertongen, F, Ferster, A, et al. Neonatal Screening and Clinical Care Programmes for Sickle Cell Disorders in Sub-saharan Africa: Lessons from Pilot Studies. Public Health (2008). 122: 933-41. doi:10.1016/j.puhe.2007.12.005

42. National Statistical Office. 2018 Malawi Population and Housing Census Main Report. Malawi: Malawi Ministry of Health (2019).

43. Ware, RE. Is Sickle Cell Anemia a Neglected Tropical Disease?. PLoS Negl Trop Dis (2013). 7:e2120. doi:10.1371/journal.pntd.0002120

44. Williams, TN, and Weatherall, DJ. World Distribution, Population Genetics, and Health burden of the Hemoglobinopathies. Cold Spring Harbor Perspect Med (2012). 2:a011692. doi:10.1101/cshperspect.a011692

Copyright (c) 2021 Tegha, Topazian, Kamthunzi, Howard, Tembo, Mvalo, Chome, Kumwenda, Mkochi, Hernandez, Ataga, Hoffman and Ware. This is an open-access article distributed under the terms of the Creative Commons Attribution License (CC BY). The use, distribution or reproduction in other forums is permitted, provided the original author(s) and the copyright owner(s) are credited and that the original publication in this journal is cited, in accordance with accepted academic practice. No use, distribution or reproduction is permitted which does not comply with these terms. 